\title{
Telephone Outreach to Increase Colon Cancer Screening in Medicaid Managed Care Organizations: A Randomized Controlled Trial
}

\author{
Allen J. Dietrich, MD \\ Jonatban N. Tobin, PbD \\ Cbristina M. Robinson, MS \\ Andrea Cassells, MPH \\ Mary Ann Greene, MS \\ Van H. Dunn, MD, MPH, FACP \\ Kimberly M. Falkenstern, MA \\ Rosanna De Leon, BS \\ Michael L. Beach, MD, $P b D^{\circ}$
}

\begin{abstract}
PURPOSE Health Plans are uniquely positioned to deliver outreach to members. We explored whether telephone outreach, delivered by Medicaid managed care organization (MMCO) staff, could increase colorectal cancer (CRC) screening among publicly insured urban women, potentially reducing disparities.

METHODS We conducted an 18-month randomized clinical trial in 3 MMCOs in New York City in 2008-2010, randomizing 2,240 MMCO-insured women, aged 50 to 63 years, who received care at a participating practice and were overdue for CRC screening. MMCO outreach staff provided cancer screening telephone support, educating patients and helping overcome barriers. The primary outcome was the number of women screened for CRC during the 18-month intervention, assessed using claims.
\end{abstract}

RESULTS MMCO staff reached $60 \%$ of women in the intervention arm by telephone. Although significantly more women in the intervention (36.7\%) than in the usual care $(30.6 \%)$ arm received CRC screening (odds ratio $[O R]=1.32 ; 95 \% \mathrm{Cl}$, $1.08-1.62$ ), increases varied from $1.1 \%$ to $13.7 \%$ across the participating MMCOs, and the overall increase was driven by increases at $1 \mathrm{MMCO}$. In an as-treated comparison, $41.8 \%$ of women in the intervention arm who were reached by telephone received CRC screening compared with $26.8 \%$ of women in the usual care arm who were not contacted during the study $(\mathrm{OR}=1.84 ; 95 \% \mathrm{Cl}, 1.38,2.44) ; 7$ women needed to be reached by telephone for 1 to become screened.

CONCLUSIONS The telephone outreach intervention delivered by MMCO staff increased CRC screening by $6 \%$ more than usual care among randomized women, and by $15.1 \%$ more than usual care among previously overdue women reached by the intervention. Our research-based intervention was successfully translated to the health plan arena, with variable effects in the participating MMCOs.

Ann Fam Med 2013;335-343. doi:10.1370/afm.1469

\section{INTRODUCTION}

Conflicts of interest: authors report none.

\section{CORRESPONDING AUTHOR}

Allen J. Dietrich, MD

Department of Community and Family Medicine

Dartmouth Hitchcock Medical Center

The Geisel School of Medicine at Dartmouth 7927 Rubin

Lebanon, NH 03756

allen.j.dietrich@dartmouth.edu olorectal cancer (CRC) remains the second leading cause of cancer death in the United States ${ }^{1}$ despite screening tests that can detect and prevent it. The United States Preventive Services Task Force (USPSTF) gives CRC screening its highest recommendation, ${ }^{2}$ and mortality from CRC has declined as screening rates have increased. ${ }^{3,4}$ Screening rates still lag for Hispanics, African Americans, low-income individuals, and immigrants, ${ }^{5-7}$ however, contributing to disparities in CRC morbidity and mortality. ${ }^{3}$

Telephone outreach, provided by practice or research-based staff or patient navigators, has increased CRC screening in many studies. ${ }^{8-21}$ Patient navigators, who commonly begin outreach after patients receive 
referrals, have played an important role in CRC outreach in New York City and elsewhere, ${ }^{11-19}$ improving screening rates particularly among patients whose primary language was not English or who were black ${ }^{18}$ or Hispanic. ${ }^{12}$

In a previous randomized controlled trial, research staff provided telephone support to women recruited in Federally qualified Community Health Centers in New York City, ${ }^{22}$ significantly increasing CRC screening rates. We then shifted from a research to a practice setting, with Medicaid managed care organization (MMCO) outreach staff delivering telephone support for CRC screening to eligible members. We could then use claims data rather than costly chart reviews to select eligible women and evaluate the intervention, to include women unlikely to be recruited from Community Health Center waiting rooms or by programs relying upon referrals, and to locate the intervention within an institution having the infrastructure and resources that potentially could sustain it. After a pilot study significantly increased CRC screening at 1 $\mathrm{MMCO}^{23}$ we launched a full randomized controlled trial in 3 different MMCOs in New York City. We report here on the results of this study.

\section{METHODS}

The study was approved with a waiver of consent by the Committee for the Protection of Human Subjects at Dartmouth College (Hanover, NH), and the institutional review boards at Clinical Directors Network, and Lutheran Medical Center. The Biomedical Research Alliance of New York, which provided human subjects review for 11 MMCOs, required Prevention Care Managers at that health plan to obtain oral consent before any telephone contact with patients. Women were informed that neither their health care nor their insurance would be compromised if they declined to speak to a Prevention Care Manager, and all patient data were de-identified.

Clinical Directors Network (http://www.CDNetwork.org) is a nonprofit, practice-based research network and clinician-training organization in New York City that conducts clinical and translational research in primary care practices caring for underserved and minority populations. Clinical Directors Network recruited MMCOs and practices, trained MMCO staff, monitored intervention delivery, and participated in data management.

\section{Setting and Participants}

Eleven federally funded Community Health Centers, 5 municipally funded diagnostic and treatment centers, and 4 private practices participated in this study, reflecting the diversity of primary care practices in New York City. Clinical Directors Network approached $8 \mathrm{MMCO}$ to discuss participation in this project, selecting $3 \mathrm{MMCO}$ plans (MMCO1, $\mathrm{MMCO} 2$, and $\mathrm{MMCO} 3$ ) who had a sufficient number of eligible members and who were willing to direct resources toward cancer screening telephone outreach. MMCOs chose to participate primarily to improve their ability to conduct effective CRC screening outreach before the addition of CRC screening to the annual New York State Quality Assurance Reporting Requirement. The New York State Department of Health's Office of Managed Care also approved this study as a Performance Improvement Project, and 2 MMCOs used it to meet this annual requirement. Each MMCO received a modest financial payment to support outreach staff and to contribute to administrative costs associated with the study.

Because the Prevention Care Management intervention was previously developed and tested among women, we chose to exclude men. Using MMCO administrative and claims data, we identified women who spoke English, Spanish, or Russian as their primary language and were aged 50 to 63 years, continuously enrolled with a participating MMCO for at least 12 months, and assigned to a participating practice. We then excluded women who were up-to-date for CRC screening according to USPSTF recommendations or with claims indicating any history of CRC, recent active cancer treatment, or a recent breast, cervical or lung cancer diagnosis. We excluded women aged 64 years and older because of concerns that Medicare eligibility at age 65 years could complicate extraction and interpretation of claims data

\section{Randomization and Intervention}

We stratified eligible women by MMCO, primary care practice, age (55 years and younger, older than 55 years), and whether they had participated in an interview about cancer screening barriers. ${ }^{24}$ We then used a random number generator to assign 3 women to the usual care arm for each woman assigned to the intervention arm. This design was chosen to maximize statistical power while working within the constraints of our research budget and MMCO resources. Primary care clinicians and MMCO data managers were blinded to patient assignments.

We revised the tools and scripts from our earlier Prevention Care Management project, ${ }^{22,25}$ incorporating information from interviews with $\mathrm{MMCO}$-enrolled women (forms and scripts available on request). Although the study focused particularly on CRC screening, Prevention Care Managers at MMCO1 and $\mathrm{MMCO} 3$ also provided support for breast and cervi- 
cal cancer screening. Telephone outreach and mailed materials from MMCO2 focused exclusively on CRC screening, because this MMCO believed their ongoing breast and cervical cancer outreach rendered additional support for these screenings redundant. At each MMCO, 2 Prevention Care Managers-ethnically diverse men and women-provided telephone outreach in English, Spanish, and (at MMCO1) Russian. Each MMCO assigned staff and allocated resources. An initial half-day training session with MMCO outreach staff focused on early cancer-detection guidelines, strategies to address screening barriers, and the Prevention Care Management intervention protocol. During 4 additional training sessions, Prevention Care Managers practiced completing intervention forms and used role-playing to practice responding to patient barriers. Monthly quality assurance meetings with Prevention Care Managers were conducted throughout the intervention period to ensure treatment fidelity.

The 18-month intervention began in December 2008 at MMCO3, and in February 2009 at MMCO1 and $\mathrm{MMCO} 2$, with the mailing of a personalized letter. This letter, signed by the medical director of each member's primary care practice, introduced the Prevention Care Manager, strongly recommended cancer screening tests, and listed overdue screenings. Telephone outreach began a week later, with Prevention Care Managers making up to 12 initial telephone call attempts, using a script to confirm screening history, address barriers, and collect demographic information. Women who were overdue for cancer screening were mailed languageappropriate educational materials and a card listing overdue screenings to share with their primary care clinician. Prevention Care Managers continued to call overdue women, addressing such barriers as competing priorities, misconceptions, and worry, as well as providing appointment reminders for up to 18 months or until women reported that they were up-to-date. Women were encouraged to speak with their primary care clinician about which screening test to use. Because previous experience indicated that women were more likely to attend appointments they had scheduled themselves, Prevention Care Managers scheduled appointments only for women specifically requesting this help.

A random subsample of women in the usual care arm received 1 telephone call during which they confirmed screening dates, provided demographic information, and were advised to follow-up with their primary care clinician regarding cancer screening. The remaining usual care women received no study contact.

\section{Outcome Measures and Follow-up}

Our primary hypothesis was that women in the intervention arm would be more likely than women in the usual care arm to receive a CRC screening test during the 18 -month intervention period (intent-to-treat).

Prior experience with MMCO-insured patients in New York City indicated that telephone numbers are not always reliable; telephone service among this population often lapses, which can make it difficult to reach a substantial proportion of the sample. In addition, usual care women who received validation calls were advised to follow-up with their primary care clinician regarding cancer screening; this advice alone may have prompted some usual care women to become screened. As a result, we designed a prespecified as-treated subgroup analysis to examine whether women in the intervention arm successfully reached by telephone were more likely to receive CRC screening than women in the usual care arm who received no study contact.

MMCO claims data, which includes payments made for medical services rendered, provided screening test dates used to determine up-to-date status, as well as data on outpatient visits and comorbidities. Final claims data were exported in January and February 2010, at least 6 months after the end of the study at each MMCO. Screening status followed USPSTF recommendations. . $26,27^{2}$

\section{Statistical Analysis}

We estimated a raw difference of $10 \%$ in CRC screening rates, which required 1,500 patients after dropouts for a power of 0.90 in our outcome analysis, assuming a type I error rate of .05. Odds ratios (ORs) with 95\% confidence intervals from multivariate logistic regression models were used as the primary comparison of up-to-date status. Bivariate outcomes were analyzed using an unadjusted $\chi^{2}$ test. We present models that adjust for age, comorbidities (diabetes, hypertension, and high cholesterol levels), visits within 18 months, insurance (Medicaid or Family Health Plus), and primary language, all at baseline. Statistical analysis was conducted using Stata 12 (StataCorp LP).

\section{RESULTS}

We assessed 4,133 women for eligibility. After excluding 1,893 women who were up-to-date, had any active cancer treatment or diagnosis or a history of CRC, there were 2,240 (54\%) eligible for randomization (Figure 1). During randomization, 1,678 were assigned to the usual care arm, and 562 women were assigned to the intervention arm.

Enrollment was driven by the number of eligible female patients at each MMCO, with $19.9 \%$ of study patients from MMCO1, 33.5\% from MMCO2, and the remaining $46.6 \%$ from $\mathrm{MMCO} 3$ (Table 1). English was the most common primary language, with between 


\section{Figure 1. Flow diagram displaying the eligibility, randomization, and follow-up of study participants.}

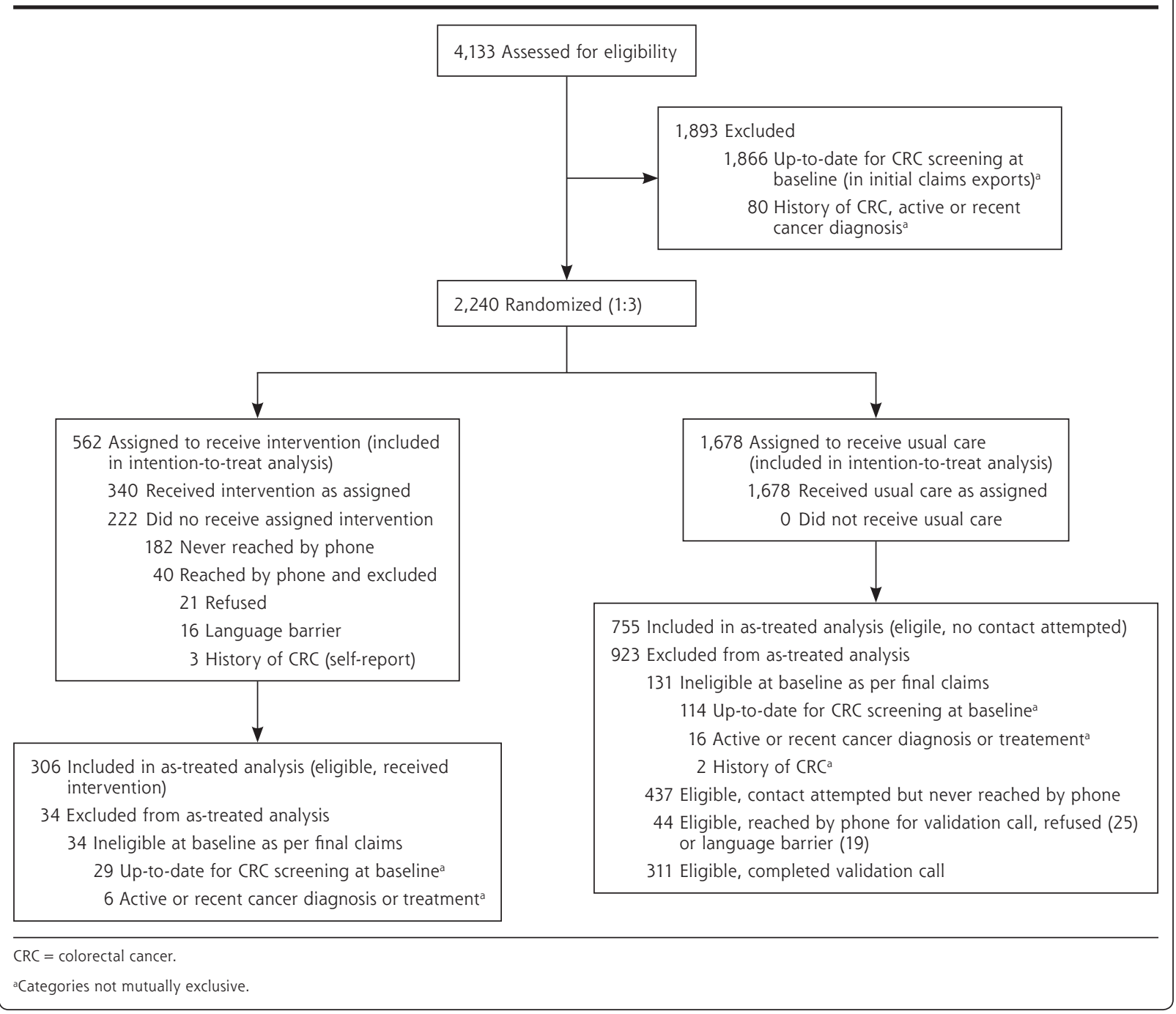

4.5\% and $36.8 \%$ at each MMCO speaking Spanish, and $13.7 \%$ at MMCO1 speaking Russian. Participating primary care practices varied in size i $_{\text {i }}$ there was an average of 24 primary care clinicians (range $=7-104$ ), and 78,963 patient encounters (range $=10,000$ $306,242)$ in 2008. Most patients of MMCO1 received their care at private practices, all patients of $\mathrm{MMCO} 2$ received their care at Community Health Centers, and most patients of $\mathrm{MMCO} 3$ received their care from diagnostic and treatment centers. Baseline CRC screening rates varied across the $3 \mathrm{MMCOs}$, from $35 \%$ at $\mathrm{MMCO} 1$ and $42 \%$ at $\mathrm{MMCO} 2$ to $57 \%$ at $\mathrm{MMCO}$.

\section{Intent-to-Treat Analysis}

There were no significant demographic differences between the 2 arms of the study (Table 2). The average woman was aged 56 years at baseline and had attended a mean number of 10 outpatient medical visits during the 18 months preceding the intervention period. Health care utilization varied widely, however, with $9 \%$ of women having no outpatient claims during this period. Approximately two-thirds of women were up-to-date for breast and cervical cancer screening at baseline.

Of the 562 women assigned to the intervention arm, MMCO outreach staff reached 60\% (340) (Figure 1) by telephone at least once $(76 \%$ at MMCO1, $60 \%$ at $\mathrm{MMCO} 2$, and $55 \%$ at $\mathrm{MMCO} 3$ ). Of these eligible women, 34 were excluded from analysis based on the final claims; 306 were reached by telephone, $61 \%$ were successfully reached for 2 or more calls $($ mean $=3$, range $=1-15)$. Initial calls averaged 13.5 minutes (range $=1-53$ minutes), and subsequent calls averaged 6.6 minutes (range $=1-21$ minutes).

Of the random subsample of women in the usual care arm, 340 received 1 telephone call, and 311 were 
eligible according to the final claims data and completed the validation call (Figure 1).

Intervention women were significantly more likely than usual care women to become up-to-date on CRC screening during the intervention period (Table 3 ), with screening rates $6 \%$ higher in the intervention arm and a significant adjusted overall OR of 1.32 (95\% CI, 1.081.62). The intervention effect varied substantially across

\section{Table 1. Characteristics of Participating Medicaid Managed Care Organizations According to Membership and Study Patients}

\begin{tabular}{|c|c|c|c|c|}
\hline Characteristic & MMCO1 & MMCO2 & MMCO3 & Total \\
\hline \multicolumn{5}{|l|}{ MMCO membership } \\
\hline \multicolumn{5}{|l|}{ Total membership in New York } \\
\hline \multicolumn{5}{|l|}{$\begin{array}{l}\text { Members in New York City cov- } \\
\text { ered by Medicaid or Family }\end{array}$} \\
\hline \multicolumn{5}{|l|}{ Study patients, No (\%) } \\
\hline \multicolumn{5}{|l|}{$\begin{array}{l}\text { Primary language (from adminis- } \\
\text { trative data) }\end{array}$} \\
\hline English & $359(80.5)$ & $442(58.9)$ & $750(71.8)$ & $1,551(69.2)$ \\
\hline Spanish & $20(4.5)$ & $276(36.8)$ & $259(24.8)$ & $555(24.8)$ \\
\hline Russian & $61(13.7)$ & $2(0.3)$ & $0(0)$ & $63(2.8)$ \\
\hline Other & $6(1.3)$ & $30(4)$ & $35(3.4)$ & $71(3.2)$ \\
\hline \multicolumn{5}{|l|}{ Practice type of study patients } \\
\hline $\begin{array}{l}\text { Publicly funded Community/ } \\
\text { Migrant Health Center }\end{array}$ & $51(11.4)$ & $750(100)$ & $217(20.8)$ & $1,018(45.4)$ \\
\hline $\begin{array}{l}\text { Publicly funded diagnostic and } \\
\text { treatment center }\end{array}$ & $0(0)$ & $0(0)$ & $827(79.2)$ & $827(36.9)$ \\
\hline Private practice & 395 (88.6) & $0(0)$ & $0(0)$ & $395(17.6)$ \\
\hline $\begin{array}{l}\text { Total number of patients in the } \\
\text { study }\end{array}$ & $446(19.9)$ & $750(33.5)$ & $1,044(46.6)$ & $2,240(100)$ \\
\hline
\end{tabular}

Table 2. Patient Characteristics From Administrative and Claims Data

\begin{tabular}{|c|c|c|}
\hline Characteristic & $\begin{array}{l}\text { Intervention } \\
\quad(n=562)\end{array}$ & $\begin{array}{l}\text { Usual Care } \\
(n=1,678)\end{array}$ \\
\hline Age at baseline, mean y & 55.8 & 55.8 \\
\hline \multicolumn{3}{|l|}{ Language, No. (\%) } \\
\hline English & $394(70.1)$ & $1,157(69.0)$ \\
\hline Spanish & $145(25.8)$ & $410(24.4)$ \\
\hline Russian & $11(2.0)$ & $52(3.1)$ \\
\hline Other & $12(2.1)$ & $59(3.5)$ \\
\hline \multicolumn{3}{|l|}{ Comorbidities at baseline, No. (\%) } \\
\hline Diabetes & $159(28.3)$ & $491(29.3)$ \\
\hline Hypertension & $348(61.9)$ & $1,013(60.4)$ \\
\hline High cholesterol level & $213(37.9)$ & $627(37.4)$ \\
\hline \multicolumn{3}{|l|}{ Baseline screening status, No. (\%) } \\
\hline Up-to-date on breast cancer screening & $356(63.3)$ & $1,072(63.9)$ \\
\hline Up-to-date on cervical cancer screening & $381(67.8)$ & $1,093(65.1)$ \\
\hline \multicolumn{3}{|l|}{ Health care utilization during 18 mo before baseline } \\
\hline Patients with no outpatient visits, No. (\%) & $56(10.0)$ & $156(9.3)$ \\
\hline Number of outpatient visits, mean No. & 10.5 & 10.3 \\
\hline $\begin{array}{l}\text { Patients with claim for health maintenance examina- } \\
\text { tion, No. (\%) }\end{array}$ & $277(49.3)$ & $794(47.3)$ \\
\hline
\end{tabular}

the 3 MMCOs, however. With the absolute difference in screening rates between intervention and usual care women ranging from $1.1 \%$ at $\mathrm{MMCO} 3(\mathrm{OR}=1.02$ $95 \% \mathrm{CI}, 0.76-1.38)$ to $13.7 \%$ at $\mathrm{MMCO} 2(\mathrm{OR}=1.98$; $95 \% \mathrm{CI}, 1.39-2.82)$, the overall increase was clearly due to significant screening increases at $\mathrm{MMCO} 2$. No significant differences in the intervention effect sizes were observed in comparisons between fully adjusted and unadjusted models of all randomized subjects.

Most of the increase in CRC screening resulted from a higher colonoscopy rate among intervention arm women compared with those in the usual care $\operatorname{arm}(26.3 \%$ intervention vs $20.3 \%$ usual care; $\mathrm{OR}=1.41$; 95\% CI, 1.12-1.77); home fecal occult blood test rates were not significantly different between the 2 arms of the study $(12.5 \%$ intervention vs $12.2 \%$ usual care, $\mathrm{OR}=1.03 ; 95 \% \mathrm{CI}, 0.76=1.38)$. Very few women were screened using sigmoidoscopy or barium enema. The intervention had no overall effect on breast (62\%) or cervical cancer $(67 \%)$ screening rates during the intervention period.

\section{As-Treated Analysis}

Our prespecified as-treated subgroup analysis compares eligible intervention women reached by telephone $(n=306)$ with eligible usual care women with whom no study contact was attempted $(\mathrm{n}=755)$. The observed effect size increased in this subgroup analysis, with a significant adjusted overall OR of 1.84 (95\% CI, 1.38-2.44) (Table 3) and significant adjusted ORs at $2 \mathrm{MMCOs}(\mathrm{OR}=1.54 ; 95 \%$ $\mathrm{CI}, 1.01-2.35$, and $\mathrm{OR}=3.11 ; 95 \%$ CI, 1.87-5.17). A number-neededto-treat analysis determined that for 1 woman to be screened for CRC, 7 women needed to be reached by telephone. Intervention arm screening rates were between $11.7 \%$ and $25.6 \%$ higher than usual care at the $3 \mathrm{MMCOs,}$ 
Table 3. Colon Cancer Screening Status During the 18-Month Intervention Period, Intervention vs Usual Care

\begin{tabular}{|c|c|c|c|c|c|c|c|}
\hline \multirow[b]{3}{*}{ Study Participants } & \multicolumn{5}{|c|}{ Up-to-Date on Colorectal Cancer Screening } & & \\
\hline & \multicolumn{2}{|c|}{ Intervention Arm } & \multicolumn{2}{|c|}{ Usual Care Arm } & \multirow{2}{*}{$\begin{array}{c}\% \\
\text { Difference }\end{array}$} & \multicolumn{2}{|c|}{ Odds Ratio (95\% Cl) } \\
\hline & No. & No. $(\%)$ & No. & No. (\%) & & Unadjusted & Adjusted $^{a}$ \\
\hline All randomized patients $(\mathrm{N}=2,240)$ & 562 & $206(36.7)$ & 1,678 & $514(30.6)$ & $6.0^{b}$ & $1.31^{\mathrm{a}}(1.07-1.61)$ & $1.32^{\mathrm{b}}(1.08-1.62)$ \\
\hline Members of MMCO1 & 112 & $28(25.0)$ & 334 & $68(20.4)$ & 4.6 & $1.30(0.76-2.21)$ & $1.32(0.79-2.22)$ \\
\hline Members of $\mathrm{MMCO} 2$ & 188 & $79(42.0)$ & 562 & $159(28.3)$ & $13.7^{c}$ & $1.84^{c}(1.28-2.62)$ & $1.98^{\circ}(1.39-2.82)$ \\
\hline Members of $\mathrm{MMCO} 3$ & 262 & $99(37.8)$ & 782 & $287(36.7)$ & 1.1 & $1.05(0.78-1.41)$ & $1.02(0.76-1.38)$ \\
\hline As-treated subset $(n=1,061)^{d}$ & 306 & $128(41.8)$ & 755 & $202(26.8)$ & $15.1^{c}$ & $1.97^{\circ}(1.47-2.62)$ & $1.84^{\mathrm{c}}(1.38-2.44)$ \\
\hline Subset members of MMCO1 & 80 & $21(26.3)$ & 144 & $21(14.6)$ & 11.7 & $2.08^{e}(1.06-4.08)$ & $1.86(0.93,3.72)$ \\
\hline Subset members of MMCO2 & 96 & $50(52.1)$ & 249 & $66(26.5)$ & $25.6^{c}$ & $3.01^{c}(1.79-5.06)$ & $3.11^{c}(1.87-5.17)$ \\
\hline Subset members of MMCO3 & 130 & $57(43.8)$ & 362 & $115(31.8)$ & $12.1^{\mathrm{e}}$ & $1.68^{e}(1.09-2.58)$ & $1.54^{\mathrm{e}}(1.01-2.35)$ \\
\hline \multicolumn{8}{|c|}{ MMCO = Medicaid managed care organization. } \\
\hline \multicolumn{8}{|c|}{$\begin{array}{l}\text { a Adjusted for age, comorbidities (diabetes, hypertension, and high cholesterol), visits within } 18 \text { months, insurance (Medicaid or Family Health Plus), and primary lan- } \\
\text { guage, all at baseline. } \\
\text { bP <.01. Bivariate outcomes analyzed using an unadjusted } x^{2} \text { test. } \\
\text { ( } P<.001 \text {. Bivariate outcomes analyzed using an unadjusted } x^{2} \text { test. } \\
\text { dThis analysis excludes women who were up-to-date at baseline or otherwise ineligible according to final electronic administrative and claims data, and compares inter- } \\
\text { vention arm women reached by telephone with usual care women with whom no study contact was attempted. } \\
\text { e } P<.05 \text {. Bivariate outcomes analyzed using an unadjusted } x^{2} \text { test. }\end{array}$} \\
\hline
\end{tabular}

with an overall increase of $15.1 \%(P<.001)$, again primarily due to screening increases at MMCO2. Relative increases in intervention screening rates over usual care ranged between $38 \%$ and $97 \%$ at the 3 MMCOs, with an overall relative increase of $56.3 \%$, again mostly due to increased colonoscopy among women in the intervention arm (32\% intervention vs $17.5 \%$ for usual care; $\mathrm{OR}=2.22 ; 95 \% \mathrm{CI}, 1.62-3.05)$. There was no significant difference in home fecal occult blood test rates $(14.7 \%$ intervention vs $11.7 \%$ usual care $; \mathrm{OR}=1.31$; 95\% CI, 0.87-1.95).

\section{DISCUSSION}

In this study, CRC screening telephone outreach was successfully delivered using internal MMCO resources rather than externally funded research staff, with CRC screening rates from one-third higher to nearly double among women receiving the intervention, varying across the 3 participating MMCOs. The impact of the intervention was similarly low at MMCO1 and MMCO3. Neither MMCO1 nor MMCO3 showed a significant effect in the intent-to-treat analysis, and although the as-treated effect was significant for $\mathrm{MMCO} 3$ and not for MMCO1, the percentage difference in screening between the intervention and usual care arms was similar at these 2 MMCOs $(11.7 \%$ and $12.1 \%)$, as were the confidence intervals. Patients and clinicians at MMCO1 differed most from those in our prior work (more Eastern European immigrants, primarily at private practices), and even though patients were easier to reach by telephone, many had strong personal preference barriers that were difficult to overcome. $\mathrm{MMCO} 3$ had the highest baseline CRC screening rate $(57 \%)$ and the strongest plan-wide CRC outreach program before the study, as well as a patient population primarily served by diagnostic and treatment centers. In addition, Prevention Care Managers at both MMCO1 and MMCO3 provided outreach for all 3 types of cancer screening-breast, cervical, and colorectal. MMCO2, with a lower baseline CRC screening rate $(42 \%)$, outreach focused exclusively on CRC screening, and a patient population closest to that with whom the Prevention Care Management intervention was initially developed (primarily Hispanic and black patients of Community Health Centers), saw the highest effect (13.7\% screening difference for intent-to-treat, 25.6\% for as-treated). With decades of experience in clinical quality improvement, Community Health Centers in New York City have well-established infrastructures and policies to support cancer screening, which may have also had a stronger impact, resulting in the higher effect size at MMCO2.

Although other CRC screening interventions have been successful with patients of health plans, to our knowledge, this intervention is the first that involved a Medicaid managed care population. In a study of 456 patients of a New York City employee health plan with tailored telephone outreach from research staff, there was a $21 \%$ difference in CRC screening rates after 6 months (27\% vs $6.1 \%) .{ }^{21}$ Other successful managed care CRC screening interventions have included automated telephone calls, which increased home fecal occult blood test screening rates by $6.5 \%$ in 6 months ${ }^{28}$ and mailed fecal immunochemical test kits, which nearly doubled colon cancer screening 
rates (35\% baseline, $69 \%$ follow-up). ${ }^{29}$ The populations in these studies, using employer-based managed care plans, however, differ substantially from the Medicaid population we studied.

In prior work, we observed ORs of 1.84 (95\% CI, 1.44-2.35) when the intervention was conducted by research staff in Community Health Centers, ${ }^{22}$ an effect comparable to the current study $(\mathrm{OR}=1.32$, $95 \% \mathrm{CI}, 1.08-1.62)$, suggesting that this intervention is reproducible across different organizational settings and populations. Potential reasons for the drop in effect from our earlier research-based randomized controlled trial include differences in health care utilization (recruiting women from Community Health Center waiting rooms rather than MMCO enrollment lists) and patient insurance status (publicly and privately insured patients rather than exclusively Medicaid), as well as competing priorities of MMCO staff as compared with dedicated research staff.

Although our initial study successfully increased breast, cervical, and CRC screening rates, ${ }^{22}$ neither breast nor cervical cancer screening rates increased significantly in the intervention arm in the 2 MMCOs that provided outreach for all 3 types of cancer screening. Because breast and cervical cancer screening has been so well promoted over the years in New York City, remaining barriers may be more persistent than those to CRC screening and may have served as distractions, preventing greater effectiveness in promoting CRC screening within MMCO1 and $\mathrm{MMCO} 3$.

In addition, in our earlier work, home fecal occult blood tests accounted for most of the increase in CRC screening rates, whereas most gains in this study came through colonoscopy. This shift from home fecal occult blood tests to colonoscopy illustrates different potential pathways to screening that can be followed by health plans or individuals with different policies and preferences; it also reflects recent trends, both in New York City and on the national level, toward colonoscopy. ${ }^{30-33}$

MMCO-incurred costs in this study included the salary for approximately $20 \%$ of 2 full-time outreach workers for 18 months, as well as staff time spent in training and quality assurance sessions, and on preparation and reconciliation of quarterly claims data exports. Potential adaptations of this intervention may allow for more efficient delivery, with comparable screening increases. Maintaining outreach momentum over 18 months proved challenging, and shorter interventions have been successful in other settings. ${ }^{11,21} \mathrm{~A}$ rolling 6-month outreach program may be a better match for busy MMCO outreach departments and members alike. A low-cost mailed reminder followed by telephone outreach to nonresponders ${ }^{34}$ could increase efficiency, as could a centralized computer- assisted outbound telephone interview system ${ }^{35}$ or call center. Telephone outreach that includes appointment reminders and bowel preparation recommendations could also increase the efficiency and quality of CRC screening by reducing high colonoscopy no-show and poor bowel preparation rates. . $^{17,19,36-38}$

\section{Limitations}

This study was conducted among urban, publicly insured women, and results cannot be generalized to a wider population. Electronic claims data were not designed for research purposes ${ }^{39}$; we could not distinguish between screening and diagnostic tests, and have no data on tests received before enrollment or after disenrollment, at free clinics, or overseas. MMCO members often change health plans ${ }^{40}$; after 18 months, $27 \%$ of study members, evenly distributed between study arms, were no longer enrolled with their baseline MMCO (ranging from 14\% to 32\% across MMCOs). Finally, this study was not designed to detect differences in the intervention effect at the plan level or to assess the institutional differences among MMCOs or participating primary care practices that may have influenced screening rates. Strengths of this dissemination and implementation study include its large sample size, its use of electronic data to assess CRC screening rates, and its focus on increasing CRC screening among an underserved and difficult to reach population-women insured by Medicaid in NYC.

Our previously proven intervention delivered by research-based staff was successfully translated to the health plan arena, with the MMCO that focused exclusively on CRC screening experiencing the largest increase in screening rates. Overall CRC screening rates increased by $6 \%$ among randomized women and by $15.1 \%$ among women reached by telephone. MMCOs are highly motivated to increase CRC screening rates among their members, and screening increases at MMCO2 of nearly $14 \%$ among previously noncompliant members and more than $25 \%$ among those reached by telephone may encourage other health plans with low CRC screening rates to undertake CRC-focused telephone outreach. This study shows that MMCOs, key players in the delivery of health care to publicly insured and underserved populations, can successfully implement interventions to increase CRC screening, reducing health care disparities among a difficult to reach population.

To read or post commentaries in response to this article, see it online at http://www.annfammed.org/content/11/4/335.

Key words: cancer screening; claims data; Medicaid

Submitted May 4, 2012; submitted, revised, September 4, 2012; accepted September 19, 2012. 
Author affiliations: Community and Family Medicine, Norris Cotton Cancer Center, The Geisel School of Medicine at Dartmouth, Lebanon, New Hampshire (Dietrich); Department of Community and Family Medicine, The Geisel School of Medicine at Dartmouth, Lebanon, NH (Robinson, Greene); Clinical Directors Network, Inc (CDN), New York, New York (Tobin, Cassells); Department of Epidemiology and Population Health, Albert Einstein College of Medicine, Bronx, NY (Tobin); Allen and Frances Adler Laboratory of Blood and Vascular Biology, The Rockefeller University Center for Clinical and Translational Science, New York, NY (Tobin); Metro Plus Health Plan, New York, NY (Dunn); United Healthcare Community Plan, New York, NY (Falkenstern); Medical Management, HealthPlus-Amerigroup, New York, NY (De Leon); Departments of Anesthesiology and Community and Family Medicine, The Geisel School of Medicine at Dartmouth, Lebanon, NH (Beach).

Funding support: The project was supported by grant \# R01CA119014 from the National Cancer Institute (NCI).

Disclaimer: The content is solely the responsibility of the authors and does not necessarily represent the official views of $\mathrm{NCl}$ or the National Institutes of Health.

Clinical trials registration: This study is registered at Clinicaltrials.gov, study \# NCT00477646

Participating practices: We wish to acknowledge the following practices for their participation: The Joseph P. Addabbo Family Health Center, Bedford Stuyvesant Family Health Center, Boro Park Medical P.C., Brownsville Multi-Service Family Health Center, Caribbean-American Family Health Center, Cumberland Diagnostic \& Treatment Center, East New York Diagnostic \& Treatment Center, Family Physician Health Center, Gouverneur HealthCare Services, Morris Heights Health Center, Morrisania Diagnostic \& Treatment Center, Park Ridge Family Health Center, Park Slope Family Health Center, Segundo Ruiz Belvis Diagnostic \& Treatment Center, Shore Road Family Health Center, Susan Levit Quality Care Diagnostic and Treatment Center, Sunset Park Family Health Center, Urban Health Plan, and the practices of Dr Robert Goodman, Dr Seth Lapin, Dr Avi Schiowitz, and Dr Emanuel Schiowitz.

Acknowledgments: We would like to acknowledge the project teams at United Healthcare Community Plan, Health Plus, and MetroPlus Health Plan; TJ Lin at Clinical Directors Network; Carrie Klabunde at the National Cancer Institute and Beverly Pasley at the New York State Department of Health for their invaluable support throughout this project, as well as Dr Harold Sox for his review of the manuscript. Each participating $\mathrm{MMCO}$ received a modest financial payment for participating in this project.

\section{References}

1. Cancer Facts and Figures. Atlanta, GA: American Cancer Society; 2011.

2. U.S. Preventive Services Task Force. Screening for colorectal cancer: U.S. Preventive Services Task Force recommendation statement. Ann Intern Med. 2008;149(9):627-637.

3. Colorectal Cancer Facts and Figures, 2011-2013. Atlanta, GA: American Cancer Society; 2011.

4. Centers for Disease Control and Prevention (CDC). Vital signs: Colorectal cancer screening, incidence, and mortality-United States, 2002-2010. MMWR Morb Mortal Wkly Rep. 2011;60(26):884-889.

5. Shih YC, Elting LS, Levin B. Disparities in colorectal screening between US-born and foreign-born populations: evidence from the 2000 National Health Interview Survey. J Cancer Ed. 2008;23(1):18-25.
6. Klabunde CN, Cronin KA, Breen N, Waldron WR, Ambs AH, Nadel MR. Trends in colorectal cancer test use among vulnerable populations in the United States. Cancer Epidemiol Biomarkers Prev. 2011;20(8):1611-1621.

7. Shavers VL, Jackson MC, Sheppard VB. Racial/ethnic patterns of uptake of colorectal screening, National Health Interview Survey 2000-2008. J Natl Med Assoc. 2010;102(7):621-635.

8. Coronado GD, Golovaty I, Longton G, Levy L, Jimenez R. Effectiveness of a clinic-based colorectal cancer screening promotion program for underserved Hispanics. Cancer. 2011;117(8):1745-1754.

9. Walsh JM, Salazar R, Nguyen TT, et al. Healthy colon, healthy life: a novel colorectal cancer screening intervention. Am J Prev Med. 2010;39(1):1-14.

10. Holden DJ, Jonas DE, Porterfield DS, Reuland D, Harris R. Systematic review: enhancing the use and quality of colorectal cancer screening. Ann Intern Med. 2010;152(10):668-676.

11. Myers RE, Hyslop T, Sifri R, et al. Tailored navigation in colorectal cancer screening. Med Care. 2008;46(9)(Suppl 1):S123-S131.

12. Chen LA, Santos S, Jandorf L, et al. A program to enhance completion of screening colonoscopy among urban minorities. Clin Gastroent Hepatol. 2008;6(4):443-450.

13. Jandorf L, Gutierrez Y, Lopez J, Christie J, Itzkowitz SH. Use of a patient navigator to increase colorectal cancer screening in an urban neighborhood health clinic. J Urban Health. 2005;82(2):216-224.

14. Christie J, Itzkowitz S, Lihau-Nkanza I, Castillo A, Redd W, Jandorf L. A randomized controlled trial using patient navigation to increase colonoscopy screening among low-income minorities. J Natl Med Assoc. 2008;100(3):278-284.

15. Percac-Lima S, Grant RW, Green AR, et al. A culturally tailored navigator program for colorectal cancer screening in a community health center: a randomized, controlled trial. J Gen Intern Med. 2009:24(2):211-217.

16. Ma GX, Shive S, Tan Y, et al. Community-based colorectal cancer intervention in underserved Korean Americans. Cancer Epidemiol. 2009;33(5):381-386.

17. Lebwohl B, Neugut Al, Stavsky E, et al. Effect of a patient navigator program on the volume and quality of colonoscopy. J Clin Gastroenterol. 2011;45(5):e47-e53.

18. Lasser KE, Murillo J, Lisboa S, et al. Colorectal cancer screening among ethnically diverse, low-income patients: a randomized controlled trial. Arch Intern Med. 2011;171(10):906-912.

19. Nash D, Azeez S, Vlahov D, Schori M. Evaluation of an intervention to increase screening colonoscopy in an urban public hospital setting. J Urban Health. 2006;83(2):231-243.

20. Dohan D, Schrag D. Using navigators to improve care of underserved patients: current practices and approaches. Cancer. 2005; 104(4):848-855.

21. Basch CE, Wolf RL, Brouse $\mathrm{CH}$, et al. Telephone outreach to increase colorectal cancer screening in an urban minority population. Am J Public Health. 2006;96(12):2246-2253.

22. Dietrich AJ, Tobin JN, Cassells A, et al. Telephone care management to improve cancer screening among low-income women: a randomized, controlled trial. Ann Intern Med. 2006;144(8):563-571.

23. Dietrich AJ, Tobin JN, Cassells A, et al. Translation of an efficacious cancer-screening intervention to women enrolled in a Medicaid managed care organization. Ann Fam Med. 2007;5(4):320-327.

24. Robinson CM, Cassells AN, Greene MA, Beach ML, Tobin JN, Dietrich AJ. Barriers to colorectal cancer screening among publicly insured urban women: no knowledge of tests and no clinician recommendation. J Natl Med Assoc. 2011;103(8):746-753.

25. National Cancer Institute Research Tested Intervention Programs. Prevention Care Management. http://rtips.cancer.gov/rtips/programDetails.do?programld $=295722$. 
26. US Preventive Services Task Force. Screening for breast cancer: US Preventive Services Task Force recommendation statement. Ann Intern Med. 2009;151(10):716-726, W-236.

27. Screening for Cervical Cancer: Recommendations and Rationale. US Preventive Services Task Force. Rockville, MD: Agency for Healthcare Research and Quality; 2003.

28. Mosen DM, Feldstein AC, Perrin N, et al. Automated telephone calls improved completion of fecal occult blood testing. Med Care. 2010;48(7):604-610.

29. Levin TR, Jamieson L, Burley DA, Reyes J, Oehrli M, Caldwell C. Organized colorectal cancer screening in integrated health care systems. Epidemiol Rev. 2011;33(1):101-110.

30. Stevens LM. A Practical Guide to Increasing Screening Colonoscopy. New York, NY: Cancer Prevention and Control Program, Bureau of Chronic Disease Prevention and Control, NYC Dept of Health and Mental Hygiene; 2006.

31. Cohen L, Desai E, Guerrero Z, Havusha A, Sliger F, Frieden T. Take Care New York: Fourth Year Progress Report. New York, NY: New York City Department of Health and Mental Hygiene; 2008.

32. Marcello R, Mortezazadeh C, Chang C, Farley T. Take Care New York 2012: Tracking the City's Progress, 2009-2010. New York, NY: New York City Department of Health and Mental Hygiene; 2011.

33. Richards CA, Kerker BD, Thorpe L, et al. Increased screening colonoscopy rates and reduced racial disparities in the New York Citywide campaign: an urban model. Am J Gastroenterol. 2011;106(11): 1880-1886.
34. Pignone $M$, Winquist $A$, Schild $L A$, et al. Effectiveness of a patient and practice-level colorectal cancer screening intervention in health plan members: the CHOICE trial. Cancer. 2011;117(15):3352-3362.

35. White MJ, Stark JR, Luckmann R, Rosal MC, Clemow L, Costanza ME. Implementing a computer-assisted telephone interview (CATI) system to increase colorectal cancer screening: a process evaluation. Patient Educ Couns. 2006;61(3):419-428.

36. Bazargan M, Ani C, Bazargan-Hejazi S, Baker RS, Bastani R. Colorectal cancer screening among underserved minority population: discrepancy between physicians' recommended, scheduled, and completed tests. Patient Educ Couns. 2009;76(2):240-247.

37. Holt CL, Schroy PC. A new paradigm for increasing use of openaccess screening colonoscopy. Clin Gastroenterol Hepatol. 2008; 6(4):377-378.

38. Kazarian ES, Carreira FS, Toribara NW, Denberg TD. Colonoscopy completion in a large safety net health care system. Clin Gastroenterol Hepatol. 2008;6(4):438-442.

39. Carney PA, Hoffman RM, Lieberman DA, Hornbrook MC, Dietrich AJ, Klabunde CN. Data systems to evaluate colorectal cancer screening practices and outcomes at the population level. Med Care. 2008;46(9)(Suppl 1):S132-S137.

40. Fairbrother G, Park HL, Haivderv A. Policies and Practices that Lead to Short Tenures in Medicaid Managed Care. New York, NY: Center for Healthcare Strategies, Inc. New York Academy of Medicine; 2004.

\section{CHANGE-OF-ADDRESS FORM FAMNILY MEDICINE}

Please complete this form and mail to the following address or fax to Annals Circulation at 913-906-6080:

Annals of Family Medicine, Circulation Department, 11400 Tomahawk Creek Pkwy, Leawood, KS 66211-2680

Check if member of sponsoring organization: $\square$ AAFP $\square$ ABFM $\square$ STFM $\square$ ADFM

\section{$\square$ AFMRD $\square$ NAPCRG $\square$ CFPC}

ID number from label on your journal cover

OLD Information (Please print.)

\begin{tabular}{lc}
\hline Name \\
\hline Company (if applicable) \\
\hline Address (Street plus Apt or Ste) \\
\hline City \\
\hline Country \\
\hline Telephone \\
\hline E-Mail & Faxtal Code (9-digit ZIP for US) \\
\hline
\end{tabular}

NEW Information (Please print.)

\begin{tabular}{ll}
\hline Name \\
\hline Company (if applicable) \\
\hline Address (Street plus Apt or Ste) \\
\hline City & Postal Code (9-digit ZIP for US) \\
\hline Country & Fax \\
\hline Telephone & \\
\hline E-Mail &
\end{tabular}

